\title{
Possible Role of Hyperinsulinemia and Insulin Resistance in Lower Vitamin D Levels in Overweight and Obese Patients
}

\author{
Giovanni De Pergola, ${ }^{1}$ Alessandro Nitti, ${ }^{1}$ Nicola Bartolomeo, ${ }^{2}$ Antonella Gesuita, ${ }^{1}$ \\ Vito Angelo Giagulli, ${ }^{3}$ Vincenzo Triggiani, ${ }^{4}$ Edoardo Guastamacchia, ${ }^{4}$ and Franco Silvestris ${ }^{1}$ \\ ${ }^{1}$ Clinical Nutrition Unit, Department of Biomedical Sciences and Human Oncology, Section of Clinical Oncology, School of Medicine, \\ University of Bari, Policlinico, Piazza Giulio Cesare 11, 70124 Bari, Italy \\ ${ }^{2}$ Department of Biomedical Sciences and Human Oncology, School of Medicine, University of Bari, Policlinico, \\ Piazza Giulio Cesare, 70124 Bari, Italy \\ ${ }^{3}$ Outpatient Clinic for Metabolic Diseases and Endocrinology, Conversano Hospital, ASL Bari, 70014 Conversano, Italy \\ ${ }^{4}$ Section of Endocrinology and Metabolic Diseases, Department of Emergency and Organ Transplantation, \\ School of Medicine, University of Bari, Policlinico, Piazza Giulio Cesare, 70124 Bari, Italy
}

Correspondence should be addressed to Giovanni De Pergola; gdepergola@libero.it

Received 5 August 2012; Revised 6 December 2012; Accepted 8 December 2012

Academic Editor: Joseph Fomusi Ndisang

Copyright (c) 2013 Giovanni De Pergola et al. This is an open access article distributed under the Creative Commons Attribution License, which permits unrestricted use, distribution, and reproduction in any medium, provided the original work is properly cited.

A cohort of 66 healthy overweight and obese patients, 53 women and 13 men were examined. Waist circumference and fasting $25(\mathrm{OH}) \mathrm{D}$, insulin, glucose, lipid (cholesterol, HDL cholesterol, and triglyceride), C-reactive protein (CRP), and complement $3\left(\mathrm{C}_{3}\right)$, and $4\left(\mathrm{C}_{4}\right)$ serum concentrations were measured. Insulin resistance was assessed by the homeostasis model assessment $\left(\mathrm{HOMA}_{\mathrm{IR}}\right)$. Results. 25(OH)D levels showed a significant negative correlation with BMI $(P<0.01)$, waist circumference $(P<0.05)$, fasting insulin $(P<0.01), \mathrm{HOMA}_{\mathrm{IR}}(P<0.01)$, triglycerides $(P<0.01)$, CRP $(P<0.01), \mathrm{C}_{3}(P<0.05)$, and $\mathrm{C}_{4}(P<0.05)$. Multiple regression analyses were performed with $25(\mathrm{OH}) \mathrm{D}$ as the dependent variable and BMI (or waist circumferences), fasting insulin (or $\mathrm{HOMA}_{\mathrm{IR}}$ ), triglycerides, and CRP (or $\mathrm{C}_{3}$ or $\mathrm{C}_{4}$ ) as independent variables. Only insulin or $\mathrm{HOMA}_{\mathrm{IR}}$ maintained a significant independent association with $25(\mathrm{OH}) \mathrm{D}$ levels, whereas vitamin $\mathrm{D}$ did not maintain a significant independent association with CRP or $\mathrm{C}_{3}$ or $\mathrm{C}_{4}$ concentrations. Conclusions. The present study, performed in overweight and obese subjects, shows that 25(OH)D levels are negatively associated with inflammatory parameters such as CRP and $\mathrm{C}_{3}$ and $\mathrm{C}_{4}$ levels, but not independently of BMI, body fat distribution, insulin levels, or insulin resistance. Our results suggest that hyperinsulinemia and/or insulin resistance are directly responsible for decrease of $25(\mathrm{OH}) \mathrm{D}$ levels in obesity.

\section{Introduction}

Vitamin D is well known to be involved in the calcium and bone metabolism, and most observational and randomized placebo-controlled trials concerning this vitamin have focused on the skeletal effects and have linked low vitamin D levels to fractures [1-3]. However, interest is growing in the nonskeletal effects of vitamin D [4] and in the relationship between vitamin $\mathrm{D}$ deficiency and diseases such as obesity, diabetes mellitus, and metabolic syndrome.

Serum 25-hydroxyvitamin D3 (25(OH)D) level reflects total vitamin $\mathrm{D}$ from dietary intake and sunlight exposure, as well as the conversion of vitamin $\mathrm{D}$ from adipose stores in the liver. Therefore, it is the best indicator of overall vitamin D status [5].

Several studies have demonstrated that serum 25(OH)D concentrations are inversely correlated with measures of obesity such as body mass index (BMI), waist circumference, and subcutaneous and visceral fat [6-10].

Insulin resistance and hyperinsulinemia are typical features of abdominal obesity, and, interestingly, inverse associations between $25(\mathrm{OH}) \mathrm{D}$ levels and fasting insulin concentrations [11-13] or insulin resistance (measured by $\mathrm{HOMA}_{\mathrm{IR}}$ index) [11-13] or insulin sensitivity index $[14,15]$ have been 
reported in most of the studies, even independently of BMI or obesity [13].

Some cross-sectional studies indicate that low vitamin D is also associated with higher serum levels of inflammatory biomarkers, such as C-reactive protein (CRP), interleukin6 (IL-6), and tumor necrosis factor $\alpha$ (TNF- $\alpha$ ) in either healthy [16-19] or obese subjects [20]. However, the relationship between vitamin $\mathrm{D}$ and inflammation is not fully clear. In fact, other studies have not confirmed an inverse relationship between vitamin $\mathrm{D}$ and inflammation parameters in normal weight [21, 22] and obese patients [23]. Moreover, when healthy overweight subjects participating in a weight-reduction program were supplemented with vitamin D (3332 IU cholecalciferol/day for twelve months), they did not show a decrease in serum CRP and IL- 6 and concentration [24]. Lastly, the National Health and Nutrition Examination Survey (2001 to 2006) observed a significant independent inverse relation between 25(OH)D and CRP levels only when $25(\mathrm{OH}) \mathrm{D}$ concentrations were lower than $21 \mathrm{ng} / \mathrm{mL}$ [25].

Obesity is characterized by a condition of low-grade chronic inflammation, and it is well known that adipocytes express TNF- $\alpha$ and may produce $30 \%-40 \%$ of circulating levels of IL-6 [26], the main regulator of CRP production in the liver. It is noteworthy that low-grade chronic inflammation is responsible for the activation of the complement system, a situation that could contribute to the metabolic complications observed in obesity. No study has investigated the relationship between $25(\mathrm{OH}) \mathrm{D}$ and complement protein circulating levels.

The complement is a system of proteins functionally interacting with each other in order to provide many of the effector functions of humoral immunity and inflammation. The central component of the complement system is the $\mathrm{C}_{3}$ fraction, as all the pathways for the activation of the system converge there. Interestingly, adipocytes are an important source of $\mathrm{C}_{3}$ production, in addition to that produced in the liver and in activated macrophages. Adipose tissue also produces all the factors of the alternative pathway for the complement activation [27], and human adipocytes express the genes that code the proteins activating the complement system [28]. A positive correlation was found between baseline insulin levels and $C_{3}$ levels [29], and serum $C_{3}$ has been considered as an inflammatory marker of insulin resistance [30]. Moreover, we recently found a direct association between waist circumference and $\mathrm{C}_{3}$ serum concentrations in overweight and obese patients, independently of insulin resistance [31].

To the best of our knowledge, no study has simultaneously evaluated vitamin $\mathrm{D}$, insulin, insulin resistance, CRP, and $\mathrm{C}_{3}$ and $\mathrm{C}_{4}$ serum levels in a population of healthy obese subjects. Therefore, the present study was addressed to examine whether CRP and $\mathrm{C}_{3}$ and $\mathrm{C}_{4}$ serum levels are associated with vitamin $\mathrm{D}$ concentrations in overweight and obese patients, independently of BMI, body fat distribution, and insulin levels, all parameters well known to influence vitamin D concentrations. To this aim, a cohort of 66 overweight and obese patients, aged $18-55$ years, were investigated.

\section{Methods}

2.1. Subject Population. The patients were consecutively enrolled at the Outpatient Clinic of Clinical Nutrition, Section of Clinical Oncology, Department of Internal Medicine and Clinical Oncology, University of Bari, School of Medicine.

Concerning the inclusion criteria, subjects were recruited at the first medical examination whether they showed a BMI higher than 25.0 and were not using any drug (including oral contraceptives for premenopausal women and hormone replacement therapy for postmenopausal women). They came to the Outpatient Clinic with the aim of losing weight and/or to have dietetic and lifestyle suggestions. Subjects were defined overweight whether they had a BMI between 25.0 and $29.9 \mathrm{~kg} / \mathrm{m}^{2}$ and obese whether they had a BMI $\geq 30 \mathrm{~kg} / \mathrm{m}^{2}$.

Patients with the following disorders were excluded: endocrinological diseases, diabetes mellitus, chronic inflammatory diseases, stable hypertension, angina pectoris, heart infarction, congenital heart disease, stroke, and transient ischemic attack. Thus, the study enrolled 66 patients, including 53 women and 13 men, aged $18-55$ years.

All subjects gave their informed consent for the study, which was performed in accordance with the guidelines proposed in the Declaration of Helsinki.

All patients had fasting blood glucose levels lower than $126 \mathrm{mg} / \mathrm{dL}$, and they were judged in good health on the basis of physical examination, medical history, routine blood work, urinalysis, and electrocardiogram. None of the patients was on hypocaloric diet or had been involved into intensive or competitive physical activity prior to the enrollment. During the testing period, all subjects were asked to keep their normal mixed diet and not to perform any sporting activity. The day before the measurement, they were abstained from both caffeinated and alcoholic drinks but maintained their normal diet.

2.1.1. Anthropometric Measurements and General Data. Body weight was measured to the nearest kg. Height was determined to the nearest $\mathrm{cm}$. BMI was calculated as the weight $(\mathrm{kg})$ divided by the square of height $(\mathrm{m})$. Waist circumference was measured at the narrowest part of the abdomen, that is, at the natural indentation between the 10th rib and the iliac crest (minimum waist).

2.1.2. Hormone and Metabolic Parameters. Blood samples were drawn between 08:00 h and 09:00 h after an overnight fast. Serum insulin concentrations were measured by radioimmunoassay (Behring, Scoppito, Italy), and intraand interassay coefficients of variation were $3.7 \%$ and $7.5 \%$, respectively. Plasma $25(\mathrm{OH}) \mathrm{D}$ was quantified by a chemiluminescence method (Diasorin Inc., Stillwater, USA), and all samples were analyzed in duplicate. The assay had intraclass CV of 5.3\%-6.7\% and interclass CV of $4.6 \%-8.7 \%$.

The $\mathrm{C}_{3}$ and $\mathrm{C}_{4}$ fractions of the complement were determined by immunonephelometry (Behring Nephelometer II (BNII); Dade-Behring, Marburg, Germany). Intra- and interassay coefficients of variation were lower than $6 \%$. CRP was measured by a particle-enhanced turbidimetric 
immunoassay (PETIA) technique (Siemens Healthcare Diagnostic Inc., Newark, DE, USA). Intra- and interassay coefficients of variation were lower than $8 \%$. It is noteworthy that this assay meets the recommendations of the American Heart Association and the Centers for Disease Control (2003) for determining patients at high risk for cardiovascular disease [32].

Plasma glucose levels were determined by the glucoseoxidase method (Sclavo, Siena, Italy). Plasma lipids (triglycerides, total cholesterol, and HDL cholesterol) were determined by an automatic colorimetric method (Hitachi; Boehringer Mannheim, Mannheim, Germany).

Insulin resistance was assessed by using the homeostasis model assessment $\left(\mathrm{HOMA}_{\mathrm{IR}}\right)$ [33].

2.2. Statistics. The sample characteristics were expressed by mean and standard deviation of the measured parameters. Variables with a skewed distribution were transformed before any statistical analyses, to improve the approximation to a Gaussian distribution: insulin, $\mathrm{HOMA}_{\mathrm{IR}}$, BMI, triglycerides, $\mathrm{CRP}$, and $\mathrm{C}_{4}$ (positively skewed) were transformed into their logarithms, while $\mathrm{C}_{3}$ (negatively skewed) was elevated to the square. Several univariate linear regression analyses were performed to test the joint effect of different variables on plasma 25(OH)D levels, and, for each model, the assumptions of linearity, the normality of the residuals (Shapiro-Wilk test), the homoskedasticity (Breusch-Pagan test), and the absence of serial correlation (Durbin-Watson value) were verified; the measures of relationships were also evaluated by Pearson's correlation coefficient. The variables having a $P$ value $<0.05$ in univariate $t$-test were selected for inclusion in multivariate linear regression model analyses. Concerning the power analysis, based on Type III $F$ test of one predictor adjusting for the other three predictors (excluding the intercept) in a regression model with a significance level of 0.05 , assuming an unconditional model with normal predictors, a sample size of 66 (i.e., the number of patients examined in the present study) has a power of 0.797. Statistical and power analyses were performed using SAS software Version 9.3 for PC.

\section{Results}

Table 1 shows the general, anthropometric, hormone, and metabolic parameters in the study population.

Table 2 shows the relationship between 25(OH)D levels and general, anthropometric, hormone, and metabolic parameters. Variables significantly predictive of $25(\mathrm{OH}) \mathrm{D}$ levels in univariate linear regression models were BMI, waist circumference, fasting insulin, $\mathrm{HOMA}_{\mathrm{IR}}$, triglycerides, CRP, $\mathrm{C}_{3}$ and $\mathrm{C}_{4}$.

Concerning multiple regression analyses, a first analysis was performed by considering $25(\mathrm{OH}) \mathrm{D}$ as the dependent variable and BMI, fasting CRP, insulin (or $\mathrm{HOMA}_{\mathrm{IR}}$ ), and triglycerides as independent variables (fitted model: $F=5.81$, $P<0.001$, adjusted $\left.R^{2}=0.237\right)$, and $25(\mathrm{OH}) \mathrm{D}$ did not maintain an independent association with CRP $(\beta=$ $-1.685, P=0.136)$. A second multiple regression analysis was performed by considering $25(\mathrm{OH}) \mathrm{D}$ as the dependent
TABLE 1: General, anthropometric, hormone, and metabolic parameters in subjects under study $(n=66)$.

\begin{tabular}{lc}
\hline Age $($ years $)$ & $36.3 \pm 11.7$ \\
Body mass index $\left(\mathrm{kg} \cdot \mathrm{m}^{-2}\right)$ & $31.7 \pm 5.0$ \\
Waist circumference $(\mathrm{cm})$ & $103.7 \pm 12.6$ \\
Systolic blood pressure $(\mathrm{mmHg})$ & $128.3 \pm 15.1$ \\
Diastolic blood pressure $(\mathrm{mmHg})$ & $86.2 \pm 10.4$ \\
25(OH)D $(\mathrm{ng} / \mathrm{mL})$ & $18.2 \pm 7.7$ \\
Fasting blood glucose $(\mathrm{mg} / \mathrm{dL})$ & $90.3 \pm 8.4$ \\
Fasting insulin $(\mu \mathrm{UI} / \mathrm{mL})$ & $18.7 \pm 8.1$ \\
HOMA $_{\mathrm{IR}}$ & $4.20 \pm 1.98$ \\
Triglycerides $(\mathrm{mg} / \mathrm{mL})$ & $90.1 \pm 51.3$ \\
HDL cholesterol $(\mathrm{mg} / \mathrm{mL})$ & $50.8 \pm 13.0$ \\
Total cholesterol $(\mathrm{mg} / \mathrm{mL})$ & $187.0 \pm 42.5$ \\
$\mathrm{CRP}(\mathrm{mg} / \mathrm{dL})$ & $0.48 \pm 0.46$ \\
$\mathrm{C}_{3}(\mathrm{~g} / \mathrm{L})$ & $1.18 \pm 0.22$ \\
$\mathrm{C}_{4}(\mathrm{~g} / \mathrm{L})$ & $0.27 \pm 0.08$ \\
\hline
\end{tabular}

$\mathrm{HOMA}_{\mathrm{IR}}$ : homeostasis model assessment.

TABLE 2: Pearson correlation coefficients of 25(OH)D levels with general, anthropometric, hormone, and metabolic parameters in subjects under study $(n=66)$.

\begin{tabular}{lc}
\hline & $25(\mathrm{OH}) \mathrm{D}(\mathrm{ng} / \mathrm{mL})$ \\
\hline Age $($ years $)$ & -0.118 \\
Body mass index $\left(\mathrm{kg} \cdot \mathrm{m}^{-2}\right)$ & $-0.346^{* *}$ \\
Waist circumference $(\mathrm{cm})$ & $-0.296^{*}$ \\
Systolic blood pressure $(\mathrm{mmHg})$ & -0.120 \\
Diastolic blood pressure $(\mathrm{mmHg})$ & -0.137 \\
Fasting blood glucose $(\mathrm{mg} / \mathrm{dL})$ & -0.149 \\
Fasting insulin $(\mu \mathrm{UI} / \mathrm{mL})$ & $-0.350^{* *}$ \\
HOMA & $-0.344^{* *}$ \\
Triglycerides $(\mathrm{mg} / \mathrm{mL})$ & $-0.343^{* *}$ \\
HDL cholesterol $(\mathrm{mg} / \mathrm{mL})$ & -0.016 \\
Total cholesterol $(\mathrm{mg} / \mathrm{mL})$ & -0.159 \\
$\mathrm{CRP}^{*}(\mathrm{mg} / \mathrm{dL})$ & $-0.320^{* *}$ \\
$\mathrm{C}_{3}(\mathrm{~g} / \mathrm{L})$ & $-0.258^{*}$ \\
$\mathrm{C}_{4}(\mathrm{~g} / \mathrm{L})$ & $-0.302^{*}$ \\
\hline
\end{tabular}

$\mathrm{HOMA}_{\mathrm{IR}}$ : homeostasis model assessment.

${ }^{*} P<0.05,{ }^{* *} P<0.01$

variable and fasting $\mathrm{C}_{3}, \mathrm{BMI}$, insulin (or $\mathrm{HOMA}_{\mathrm{IR}}$ ), and triglycerides as independent variables (fitted model: $F=$ 5.73, $P<0.001$, adjusted $\left.R^{2}=0.240\right)$, and $25(\mathrm{OH}) \mathrm{D}$ did not maintain an independent association with $C_{3}(\beta=$ $-2.702, P=0.158)$. A third multiple regression analysis was performed by considering $25(\mathrm{OH}) \mathrm{D}$ as the dependent variable and fasting $\mathrm{C}_{4}, \mathrm{BMI}$, insulin (or $\mathrm{HOMA}_{\mathrm{IR}}$ ), and triglycerides as independent variables (fitted model: $F=5.06$, $P=0.001$, adjusted $\left.R^{2}=0.213\right)$, and $25(\mathrm{OH}) \mathrm{D}$ did not maintain an independent association with $\mathrm{C}_{4}(\beta=-1.108$, $P=0.755)$. 25(OH)D maintained a significant independent association only with insulin $(P<0.05)$ or $\mathrm{HOMA}_{\mathrm{IR}}$ $(P<0.05)$, but not with BMI and triglycerides, in all of these multiple regressions. 


\section{Discussion}

At the best of our knowledge, this is the first study examining the relationship between complement factors and vitamin $\mathrm{D}$ levels in apparently healthy overweight and obese subjects.

We show that serum vitamin $\mathrm{D}$ levels are negatively related to $\mathrm{C}_{3}$ and $\mathrm{C}_{4}$ concentrations, but these correlations were not maintained after adjustment for BMI, insulin levels, and insulin resistance. Seemingly, as previously shown in severely obese patients [20], vitamin D and CRP levels were inversely associated, but also this correlation was not maintained after adjustment for BMI, insulin, and insulin resistance, suggesting that the negative association between vitamin $\mathrm{D}$ and investigated inflammation parameters (CRP and $\mathrm{C}_{3}$ and $\mathrm{C}_{4}$ ) is only indirectly mediated by factors associated with obesity.

According to previous studies [4-10], we found an inverse correlation between vitamin D levels and BMI (or waist circumference). As far as the mechanism why obese individuals have lower serum 25(OH)D concentrations, 25(OH)D has a high lipid-solubility, and it may well be that this vitamin is under sequestration when adipose tissue is in excess, resulting in reduced $25(\mathrm{OH}) \mathrm{D}$ bioavailability [34]. In line with this hypothesis, weight loss of $10 \%$, obtained by a $20-$ week low-calorie diet, increased $25(\mathrm{OH}) \mathrm{D}$ levels in obese women [35]. Another study confirmed that serum vitamin $\mathrm{D}$ levels were higher after weight loss induced by a 2 -year dietary intervention [36]. An alternate explanation is that higher leptin and IL-6 circulating levels, mostly secreted by adipose tissue, may have inhibitory effects on $25(\mathrm{OH}) \mathrm{D}$ synthesis via their receptors [37].

According to previous studies [11-16], we also found a negative correlation between vitamin $\mathrm{D}$ levels and insulin levels and insulin resistance (measured by $\mathrm{HOMA}_{\mathrm{IR}}$ ). It is noteworthy that insulin or $\mathrm{HOMA}_{\mathrm{IR}}$ was the only parameter maintaining an inverse relationship with vitamin $\mathrm{D}$ levels independently of other variables significantly correlated with vitamin $\mathrm{D}$ in this study (BMI, waist circumference, triglycerides, CRP, and $\mathrm{C}_{3}$ and $\mathrm{C}_{4}$ ).

These results suggest that hyperinsulinemia and insulin resistance drive the negative association between serum vitamin $\mathrm{D}$ and inflammation parameters (CRP, and $\mathrm{C}_{3}$ and $\mathrm{C}_{4}$ ) in obesity.

This is the first study raising the possibility that higher insulin levels and/or insulin resistance are directly responsible for lower vitamin $\mathrm{D}$ levels, but we do not have our own data to explain this result, and this is the limitation of this study. How hyperinsulinemia can cause a decrease in plasma vitamin $\mathrm{D}$ concentration needs to be addressed further, and this may be the direction of future studies in the obesity research area. However, it may well be that hyperinsulinemia per se or nonalcoholic fatty liver disease (NAFLD) associated with insulin resistance inhibits the activity of liver 25-hydroxylase, thus explaining lower production and circulating levels of $25(\mathrm{OH}) \mathrm{D}$ in obesity.

Interestingly, since low vitamin $\mathrm{D}$ is a risk factor for diabetes mellitus [38], it may well be that the effect of hyperinsulinemia on vitamin D levels may be one of the mechanisms that through insulin resistance enhances the risk of diabetes.
How low plasma vitamin D levels can change insulin concentration and sensitivity has been shown. In fact, vitamin D increases both insulin secretion $[39,40]$ and insulin sensitivity. Concerning insulin secretion, vitamin $\mathrm{D}$ receptors are expressed in both pancreatic $\beta$-cells and skeletal muscle cells, and vitamin D supplementation results in increased insulin release and insulin-mediated glucose transport [41]. Concerning the possible influence of vitamin $\mathrm{D}$ on insulin effect, two randomized controlled trials of high-dose vitamin D supplementation showed a significant increase in insulin sensitivity in insulin-resistant Indian men or South-Asian women, either after 6 weeks or 6 months of treatment, respectively $[42,43]$. Interestingly, in vitro studies have even shown that vitamin D may influence insulin sensitivity via a direct stimulatory effect on insulin receptor expression [44].

In conclusion, the present study shows for the first time that vitamin $\mathrm{D}$ is negatively related to complement factor $\left(\mathrm{C}_{3}\right.$ and $\left.\mathrm{C}_{4}\right)$ levels. These correlations were not maintained after adjustment for BMI (or waist circumference), insulin (or $\mathrm{HOMA}_{\mathrm{IR}}$ ), and triglyceride levels, and, in particular, only insulin and $\mathrm{HOMA}_{\mathrm{IR}}$ maintained an inverse relationship with vitamin $\mathrm{D}$ levels independently of other variables. Therefore, our study strongly suggests that hyperinsulinemia and insulin resistance are the main factors responsible for decrease of vitamin $\mathrm{D}$ concentrations in obese patients.

\section{References}

[1] M. F. Holick, "Medical progress: vitamin D deficiency," The New England Journal of Medicine, vol. 357, no. 3, pp. 266-281, 2007.

[2] B. Dawson-Hughes, "Serum 25-hydroxyvitamin D and functional outcomes in the elderly," American Journal of Clinical Nutrition, vol. 88, no. 2, pp. S537-S540, 2008.

[3] N. M. van Schoor, M. Visser, S. M. F. Pluijm, N. Kuchuk, J. H. Smit, and P. Lips, "Vitamin D deficiency as a risk factor for osteoporotic fractures," Bone, vol. 42, no. 2, pp. 260-266, 2008.

[4] S. Nagpal, S. Na, and R. Rathnachalam, "Noncalcemic actions of vitamin D receptor ligands," Endocrine Reviews, vol. 26, no. 5, pp. 662-687, 2005.

[5] C. J. Rosen, "Vitamin D insufficiency," The New England Journal of Medicine, vol. 364, no. 3, pp. 248-254, 2011.

[6] S. J. Parikh, M. Edelman, G. I. Uwaifo et al., "The relationship between obesity and serum 1,25-dihydroxy vitamin D concentrations in healthy adults," Journal of Clinical Endocrinology and Metabolism, vol. 89, no. 3, pp. 1196-1199, 2004.

[7] S. Cheng, J. M. Massaro, C. S. Fox et al., "Adiposity, cardiometabolic risk, and vitamin D status: the framingham heart study," Diabetes, vol. 59, no. 1, pp. 242-248, 2010.

[8] A. G. Need, P. D. O'Loughlin, M. Horowitz, and B. E. C. Nordin, "Relationship between fasting serum glucose, age, body mass index and serum 25 hydroxyvitamin D in postmenopausal women," Clinical Endocrinology, vol. 62, no. 6, pp. 738-741, 2005.

[9] S. Konradsen, H. Ag, F. Lindberg, S. Hexeberg, and R. Jorde, "Serum 1,25-dihydroxy vitamin D is inversely associated with body mass index," European Journal of Nutrition, vol. 47, no. 2, pp. 87-91, 2008. 
[10] E. Liu, J. B. Meigs, A. G. Pittas et al., "Predicted 25-hydroxyvitamin D score and incident type 2 diabetes in the Framingham Offspring Study,' American Journal of Clinical Nutrition, vol. 91, no. 6, pp. 1627-1633, 2010.

[11] R. Scragg, M. Sowers, and C. Bell, "Serum 25-hydroxyvitamin $\mathrm{D}$, diabetes, and ethnicity in the Third National Health and Nutrition Examination Survey," Diabetes Care, vol. 27, no. 12, pp. 2813-2818, 2004.

[12] L. Lu, Z. Yu, A. Pan et al., "Plasma 25-hydroxyvitamin D concentration and metabolic syndrome among middle-aged and elderly Chinese individuals," Diabetes Care, vol. 32, no. 7, pp. 1278-1283, 2009.

[13] G. Zhao, E. S. Ford, and C. Li, "Associations of serum concentrations of 25-hydroxyvitamin D and parathyroid hormone with surrogate markers of insulin resistance among U.S. adults without physician-diagnosed diabetes: NHANES, 2003-2006," Diabetes Care, vol. 33, no. 2, pp. 344-347, 2010.

[14] E. Liu, J. B. Meigs, A. G. Pittas et al., "Plasma 25-hydroxyvitamin $\mathrm{D}$ is associated with markers of the insulin resistant phenotype in nondiabetic adults," Journal of Nutrition, vol. 139, no. 2, pp. 329-334, 2009.

[15] K. C. Chiu, A. Chu, V. L. W. Go, and M. F. Saad, "Hypovitaminosis $\mathrm{D}$ is associated with insulin resistance and $\beta$ cell dysfunction," American Journal of Clinical Nutrition, vol. 79, no. 5, pp. 820-825, 2004.

[16] K. L. Jablonski, M. Chonchol, G. L. Pierce, A. E. Walker, and D. R. Seals, "25-Hydroxyvitamin D deficiency is associated with inflammation-linked vascular endothelial dysfunction in middle-aged and older adults," Hypertension, vol. 57, no. 1, pp. 63-69, 2011.

[17] C. A. Peterson and M. E. Heffernan, "Serum tumor necrosis factor-alpha concentrations are negatively correlated with serum $25(\mathrm{OH}) \mathrm{D}$ concentrations in healthy women," Journal of Inflammation, vol. 5, article no. 10, 2008.

[18] D. T. Ngo, A. L. Sverdlov, J. J. McNeil, and J. D. Horowitz, "Does vitamin $\mathrm{D}$ modulate asymmetric dimethylarginine and Creactive protein concentrations?" American Journal of Medicine, vol. 123, no. 4, pp. 335-341, 2010.

[19] H. Dobnig, S. Pilz, H. Scharnagl et al., "Independent association of low serum 25-hydroxyvitamin D and 1,25-dihydroxyvitamin D levels with all-cause and cardiovascular mortality," Archives of Internal Medicine, vol. 168, no. 12, pp. 1340-1349, 2008.

[20] A. Bellia, C. Garcovich, M. D’Adamo et al., "Serum 25hydroxyvitamin Dlevels are inversely associated with systemic inflammation in severe obese subjects," Internal and Emergency Medicine. In press.

[21] E. Hyppönen, D. Berry, M. Cortina-Borja, and C. Power, "25Hydroxyvitamin D and pre-clinical alterations in inflammatory and hemostatic markers: a cross sectional analysis in the 1958 British Birth Cohort," PloS one, vol. 5, no. 5, Article ID e10801, 2010.

[22] C. A. Peterson and M. E. Heffernan, "Serum tumor necrosis factor-alpha concentrations are negatively correlated with serum $25(\mathrm{OH}) \mathrm{D}$ concentrations in healthy women," Journal of Inflammation, vol. 5, article no. 10, 2008.

[23] N. Vilarrasa, J. Vendrell, J. Maravall et al., "Is plasma 25(OH) $\mathrm{D}$ related to adipokines, inflammatory cytokines and insulin resistance in both a healthy and morbidly obese population?" Endocrine, vol. 38, no. 2, pp. 235-242, 2010.

[24] A. Zittermann, S. Frisch, H. K. Berthold et al., "Vitamin D supplementation enhances the beneficial effects of weight loss on cardiovascular disease risk markers," American Journal of Clinical Nutrition, vol. 89, no. 5, pp. 1321-1327, 2009.

[25] M. Amer and R. Qayyum, "Relation between serum 25hydroxyvitamin D and C-reactive protein in asymptomatic adults (from the continuous National Health and Nutrition Examination Survey 2001 to 2006)," American Journal of Cardiology, vol. 109, pp. 226-230, 2012.

[26] V. Mohamed-Ali, S. Goodrick, A. Rawesh et al., "Subcutaneous adipose tissue releases interleukin-6, but not tumor necrosis factor- $\alpha$, in vivo," Journal of Clinical Endocrinology and Metabolism, vol. 82, no. 12, pp. 4196-4200, 1997.

[27] B. G. Gabrielsson, J. M. Johansson, M. Lönn et al., "High expression of complement components in omental adipose tissue in obese men," Obesity Research, vol. 11, no. 6, pp. 699-708, 2003.

[28] H. A. Koistinen, H. Vidal, S. L. Karonen et al., "Plasma acylation stimulating protein concentration and subcutaneous adipose tissue C3 mRNA expression in nondiabetic and type 2 diabetic men," Arteriosclerosis, Thrombosis, and Vascular Biology, vol. 21, no. 6, pp. 1034-1039, 2001.

[29] A. Muscari, G. Massarelli, L. Bastagli et al., "Relationship of serum C3 to fasting insulin, risk factors and previous ischaemic events in middle-aged men," European Heart Journal, vol. 21, no. 13, pp. 1081-1090, 2000

[30] A. Muscari, S. Antonelli, G. Bianchi et al., "Serum C3 is a stronger inflammatory marker of insulin resistance than Creactive protein, leukocyte count, and erythrocyte sedimentation rate: Comparison study in an elderly population," Diabetes Care, vol. 30, no. 9, pp. 2362-2368, 2007.

[31] G. De Pergola, M. M. Ciccone, P. Guida et al., "Relationship between C3 levels and common carotid intima-media thickness in overweight and obese patients," Obesity Facts, vol. 4, no. 2, pp. 159-163, 2011.

[32] T. A. Pearson, G. A. Mensah, R. W. Alexander et al., "Markers of inflammation and cardiovascular disease: Application to clinical and public health practice: a statement for healthcare professionals from the centers for disease control and prevention and the American Heart Association," Circulation, vol. 107, no. 3, pp. 499-511, 2003.

[33] E. Bonora, G. Targher, M. Alberiche et al., "Homeostasis model assessment closely mirrors the glucose clamp technique in the assessment of insulin sensitivity: studies in subjects with various degrees of glucose tolerance and insulin sensitivity," Diabetes Care, vol. 23, no. 1, pp. 57-63, 2000.

[34] J. Wortsman, L. Y. Matsuoka, T. C. Chen, Z. Lu, and M. F. Holick, "Decreased bioavailability of vitamin D in obesity," American Journal of Clinical Nutrition, vol. 72, no. 3, pp. 690-693, 2000.

[35] T. Tzotzas, F. G. Papadopoulou, K. Tziomalos et al., "Rising serum 25-hydroxy-vitamin D levels after weight loss in obese women correlate with improvement in insulin resistance," Journal of Clinical Endocrinology and Metabolism, vol. 95, no. 9, pp. 4251-4257, 2010.

[36] D. R. Shahar, D. Schwarzfuchs, D. Fraser et al., "Dairy calcium intake, serum vitamin $\mathrm{D}$, and successful weight loss," American Journal of Clinical Nutrition, vol. 92, no. 5, pp. 1017-1022, 2010.

[37] C. Ding, V. Parameswaran, L. Blizzard, J. Burgess, and G. Jones, "Not a simple fat-soluble vitamin: changes in serum 25-(OH)D levels are predicted by adiposity and adipocytokines in older adults," Journal of Internal Medicine, vol. 268, no. 5, pp. 501-510, 2010. 
[38] G. De Pergola, A. Ammirati, D. Caccavo, S. Bavaro, and G. Barone, "Vitamin D, obesity and risk of diabetes," Nutritional Therapy and Metabolism, vol. 30, no. 2, pp. 59-66, 2012.

[39] B. J. Boucher, N. Mannan, K. Noonan, C. N. Hales, and S. J. W. Evans, "Glucose intolerance and impairment of insulin secretion in relation to vitamin D deficiency in East London Asians," Diabetologia, vol. 38, no. 10, pp. 1239-1245, 1995.

[40] S. Kayaniyil, R. Vieth, R. Retnakaran et al., "Association of vitamin $\mathrm{D}$ with insulin resistance and $\beta$-cell dysfunction in subjects at risk for type 2 diabetes," Diabetes Care, vol. 33, no. 6, pp. 1379-1381, 2010.

[41] A. M. Borissova, T. Tankova, G. Kirilov, L. Dakovska, and R. Kovacheva, "The effect of vitamin D3 on insulin secretion and peripheral insulin sensitivity in type 2 diabetic patients," International Journal of Clinical Practice, vol. 57, no. 4, pp. 258-261, 2003.

[42] J. Nagpal, J. N. Pande, and A. Bhartia, "A double-blind, randomized, placebo-controlled trial of the short-term effect of vitamin D3 supplementation on insulin sensitivity in apparently healthy, middle-aged, centrally obese men," Diabetic Medicine, vol. 26, no. 1, pp. 19-27, 2009.

[43] P. R. Von Hurst, W. Stonehouse, and J. Coad, "Vitamin D supplementation reduces insulin resistance in South Asian women living in New Zealand who are insulin resistant and vitamin D deficient-a randomised, placebo-controlled trial," British Journal of Nutrition, vol. 103, no. 4, pp. 549-555, 2010.

[44] B. Maestro, J. Campión, N. Dávila, and C. Calle, "Stimulation by 1,25-dihydroxyvitamin D3 of insulin receptor expression and insulin responsiveness for glucose transport in U-937 human promonocytic cells," Endocrine Journal, vol. 47, no. 4, pp. $383-391,2000$. 


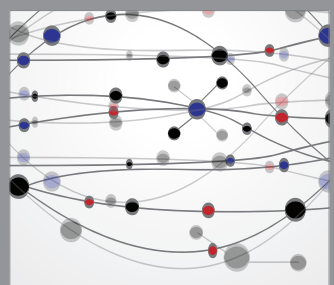

The Scientific World Journal
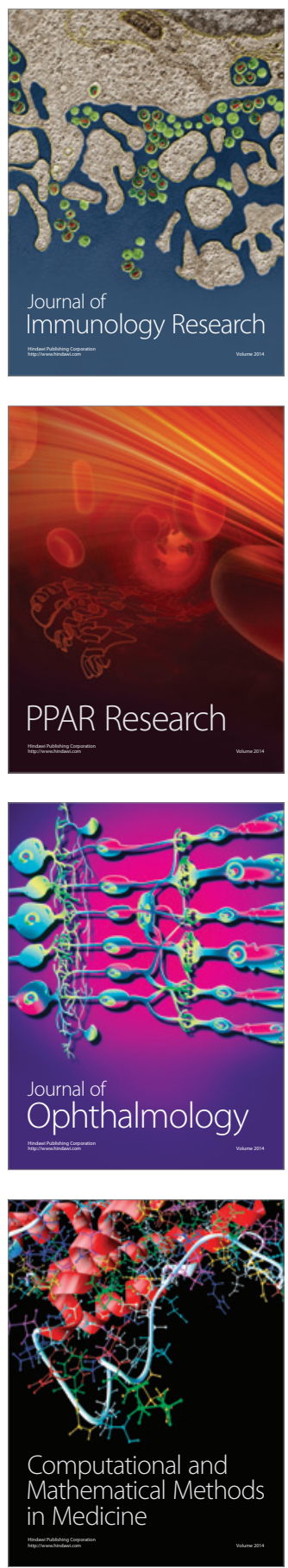

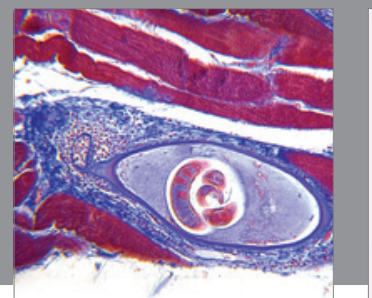

Gastroenterology

Research and Practice
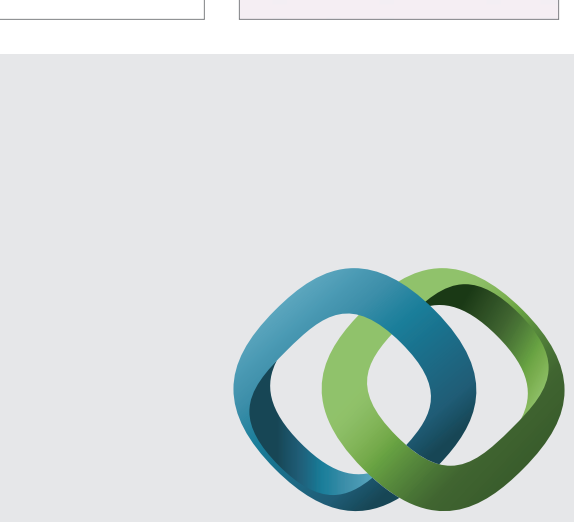

\section{Hindawi}

Submit your manuscripts at

http://www.hindawi.com
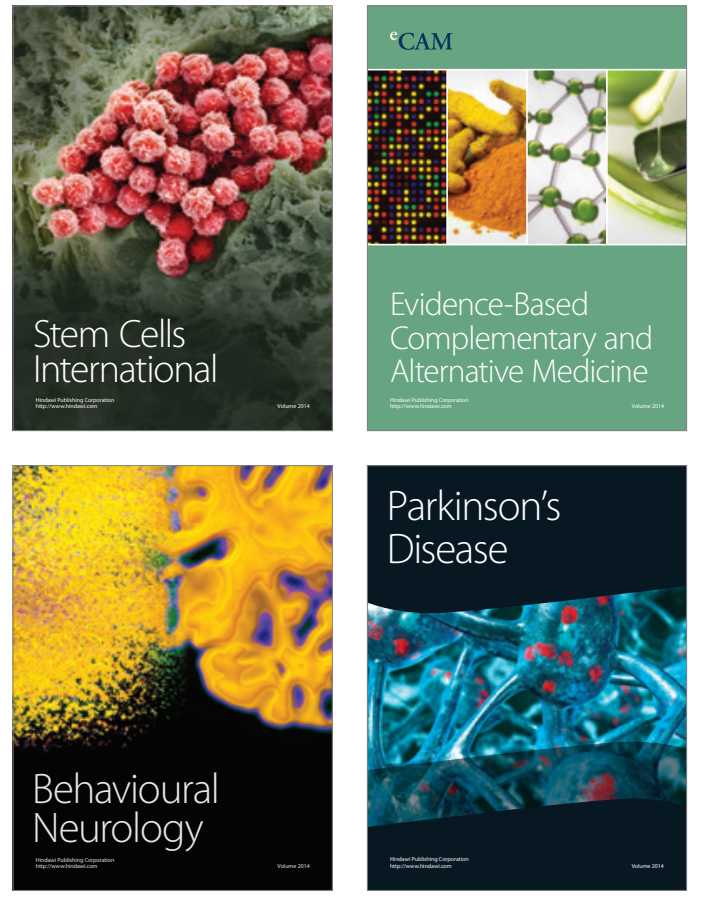
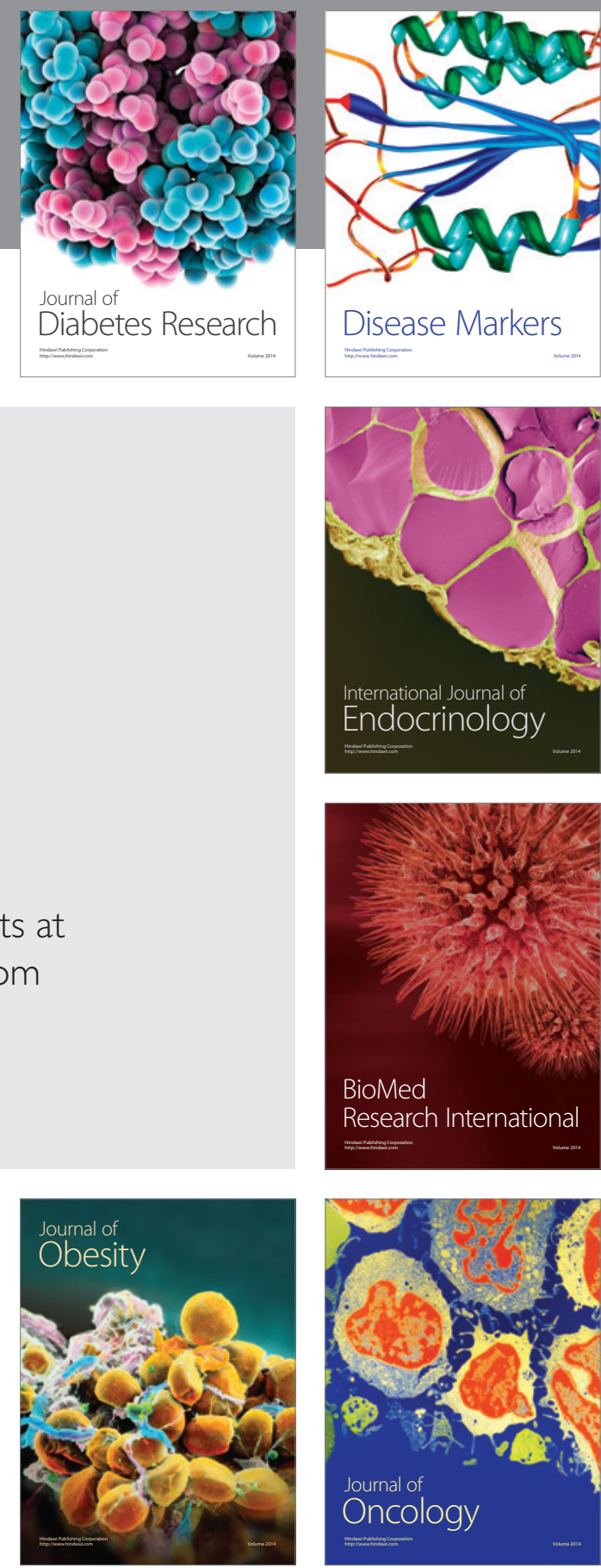

Disease Markers
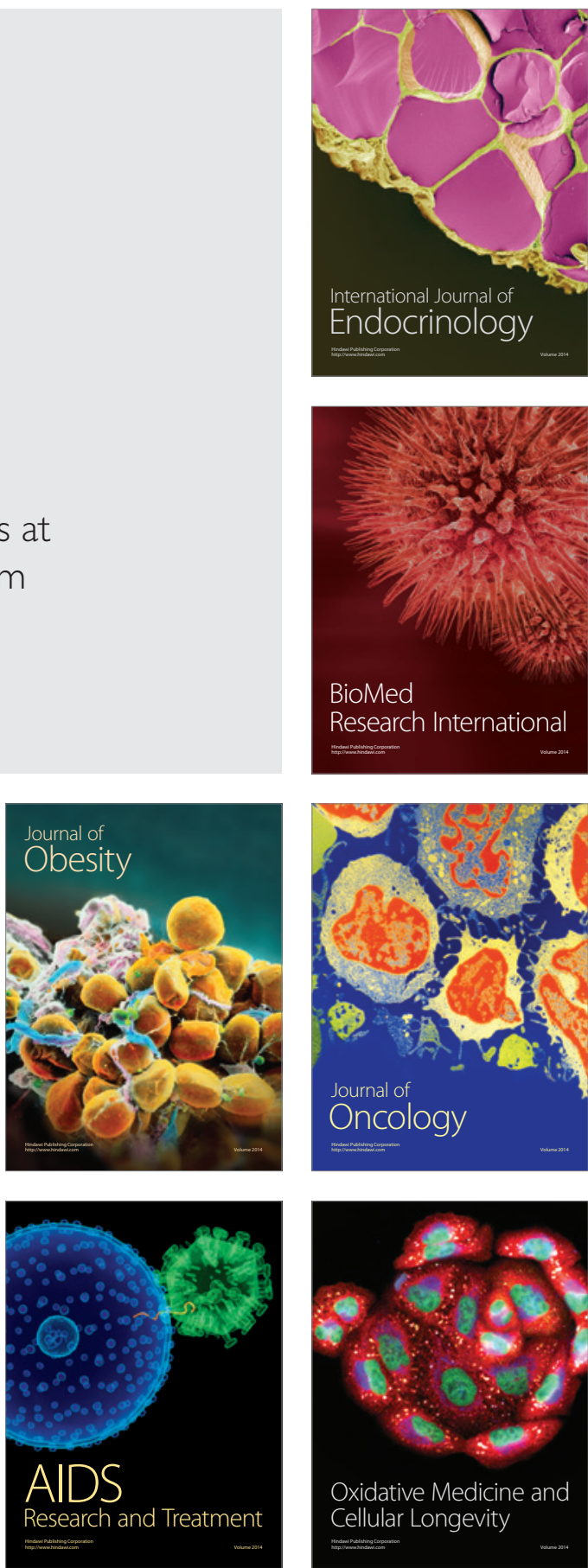